\title{
Meaning-making of female genital cutting: children's perception and acquired knowledge of the ritual
}

This article was published in the following Dove Press journal:

International Journal of Women's Health

13 April 2013

Number of times this article has been viewed

\section{Jon-Håkon Schultz Inger-Lise Lien}

Norwegian Center for Violence and Traumatic Stress Studies, Oslo, Norway

Video abstract

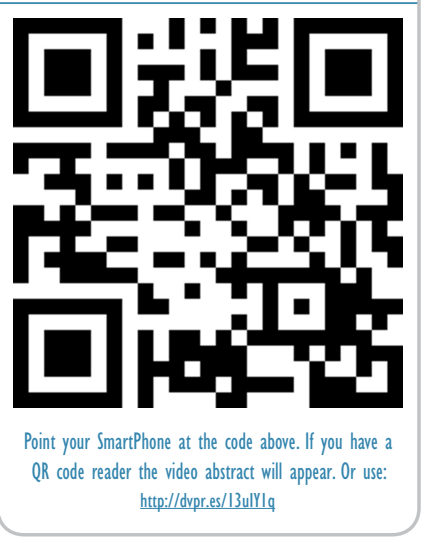

Correspondence: Jon-Håkon Schultz Norwegian Center for Violence and Traumatic Stress Studies, Kirkeveien I66, Building 48, 0407 Oslo, Norway

Tel +4793483440

$\mathrm{Fax}+4722595501$

Email j.h.schultz@nkvts.unirand.no

\begin{abstract}
How do girls who have undergone female genital cutting understand the ritual? This study provides an analysis of the learning process and knowledge acquired in their meaningmaking process. Eighteen participants were interviewed in qualitative indepth interviews. Women in Norway, mostly with Somali or Gambian backgrounds, were asked about their experiences of circumcision. Two different strategies were used to prepare girls for circumcision, ie, one involving giving some information and the other keeping the ritual a secret. Findings indicate that these two approaches affected the girls' meaning-making differently, but both strategies seemed to lead to the same educational outcome. The learning process is carefully monitored and regulated but is brought to a halt, stopping short of critical reflexive thinking. The knowledge tends to be deeply internalized, embodied, and morally embraced. The meaning-making process is discussed by analyzing the use of metaphors and narratives. Given that the educational outcome is characterized by limited knowledge without critical reflection, behavior change programs to end female genital cutting should identify and implement educational stimuli that are likely to promote critical reflexive thinking.
\end{abstract}

Keywords: female genital cutting, metaphors, health education, immigrants

\section{Introduction}

Female genital cutting (FGC) is still widely practiced, with some 140 million women worldwide estimated to have undergone this ritual, and about three million girls being circumcised each year, ${ }^{1}$ with significant geographic and local variations in ritual and procedure. Studies have noted changes in the tradition, both locally and in exile. ${ }^{2,3}$ The underlying meaning of the ritual also seems to vary and is subject to change. Commonly reported rationales for FGC are to purify the body, prepare the girl for reproductive maturity, and mark her belonging to a social group. The procedure may be performed on infants or, more commonly, on girls aged 4-10 years. In order to understand the ritual of circumcision, we need to explore its social meaning in the cultural context. From studies in Sudan, Boddy ${ }^{4}$ argues that circumcision of boys and girls can be viewed together as a model of gender complementarity. Several ethnic groups perceive children as being born "unfinished". For instance, in Mali, Sudan, and Egypt, circumcision is performed to complete the social or spiritual definition of a child's gender by removing anatomical traces of ambiguity. The Sudanese remove the girl's "masculine" clitoris and labia, and the "feminine" foreskin of boys. In girls, excision of the clitoris is followed by infibulations designed to "cover" and protect the female reproductive tract, whereas the male's organ is "opened" or "unveiled". 
Once circumcised, boys and girls live more segregated lives; they are treated differently, and their complementary dispositions mature. ${ }^{4,5}$

Studies in Somalia report that the parts of the body that are cut off are considered "childish" and "unclean". "They have to be removed in order to humanize and feminize the woman, to secure her moral uprightness and bodily beauty (...). It elevates her body to an aesthetic ideal and only as a 'sewn' woman may she represent her family later in life at marriage". ${ }^{6}$ Some Somali women state the case in religious terms, seeing circumcision as a cleansing ritual that allows them to be "true Muslims" and helps them to pray properly. It is also believed that female circumcision curbs abnormal sexual desire, making women more dedicated wives and mothers. $^{3}$

In explaining the continuation of $\mathrm{FGC}, \mathrm{Mackie}^{7}$ and Mackie and LeJeune ${ }^{8}$ employ a convention model based on Schelling 9 and assume that all parents desire to raise their children successfully and that they make decisions with the best interests of the child in mind. Female circumcision, according to this view, can be understood as a strategy for optimizing the girl's future within a cultural context. Parents love their children and make the strategic choice to circumcise their daughters in order to enable them to get married and enhance their prospects of a good life.

Among the Madinga, the social meaning of female circumcision is related to and interwoven with initiation rituals. Female circumcision as practiced by the Madinga took place historically within the context of initiation rituals. As one of the gradual steps in the transformation from childhood towards adulthood, the initiation involved an instruction period in the bush lasting up to four months, followed by public "coming out" dances. The circumcision of girls and boys is seen as being connected to the initiation rituals, even though few girls and boys experience these events simultaneously, and others might experience only the circumcision without other initiation rituals. ${ }^{3,10}$ Finally, several studies indicate how FGC has changed, with the procedure being performed on younger girls and with less ritual fanfare than before, possibly because of increased parental fears of outside intervention. Other reasons mentioned for separating female circumcision from initiation rituals are socioeconomic changes owing to urbanization and modernization. . $^{3,4,11}$

Boddy ${ }^{4}$ explains that Sudanese children are circumcised when they are old enough to have achieved a minimum of reason or "social sense". "They are expected to realize that their bodies are being 'purified', made discrete by the social group". ${ }^{4}$ Here a requirement for circumcision is that the child should be cognitively mature enough to understand the procedure. However, in other communities, circumcision is performed on infants, which means the instruction of the child and the meaning-making are initiated long after the procedure itself. The framework of knowledge which girls are supposed to understand seems to be that circumcision produces moral individuals by purifying their bodies and fostering virginity; further, it ensures girls are officially included in society, and prepares them for becoming adults and later wives and mothers. This knowledge has to be acquired by the child with seemingly little formal instruction or explanation.

Collective understandings of FGC and the meanings ascribed to it by various ethnic groups have been the subject of comprehensive studies in which the rituals have been compared and viewed from an abstract and theoretical perspective. Less research has focused on the individuals who undergo the ritual, and how they make meaning of it. Indeed, the child's perspective seems almost nonexistent in the literature. In addition to dealing with questions of cultural understanding, there has been research on the long-term damage to health and on the rights of adult women. There has been scant focus on elucidating how girls receive teaching and develop an understanding of FGC, or how they later manage to integrate the experience of FGC and develop an identity as a cut, proud, and honorable woman.

In recent decades, there has been an increased commitment to reducing and ending the practice of FGC. Nineteen African countries have implemented laws against the practice, and there are local action plans, national and international strategy plans, and a variety of information campaigns and behavior-change programs. Elements of education are integrated and appear to be a central component in the programs. ${ }^{12}$ Evaluation research indicates that education, when appropriately organized and presented within a wider process of social mobilization, can be a powerful and effective means of facilitating rapid change in the longstanding traditional behaviors of FGC. ${ }^{13}$ Although a wide variety of approaches and methods designed to end FGC are in use, ${ }^{12,14,15}$ few have been systematically evaluated. ${ }^{13,16}$ An understanding of the learning process and the type and quality of girls' acquired knowledge of the ritual is of relevance to the key education component of behavior-change programs, both in FGC-performing countries and programs targeting those living in exile in nonperforming countries.

The aim of this study was to explore the meaning-making of FGC for girls who undergo the ritual. The study analyzes the learning process and the characteristics of the knowledge the girls acquire. Two different strategies used to prepare girls 
for circumcision are analyzed, ie, according to one strategy the girls are prepared in advance, whereas in the case of the other, the ritual is shrouded in secrecy.

\section{Materials and methods Participants}

Purposive sampling was used to increase the range of data available on the two strategies for preparing the girl child. Potential informants were approached individually through Somali and Gambian networks after key persons within the networks had provided information about the research project. The selection criterion for the 18 women (aged $32-60$ years) was that they had undergone FGC. The majority had either Somali or Gambian ethnic backgrounds, although four were from neighboring countries. They were all living in Norway at the time of the interview. The study was also informed by several research trips to the Gambia, Ethiopia, and Kenya, where we systematically interviewed doctors, nurses, religious leaders, elders, circumcisers, and anticircumcision activists. These interviews serve to enlighten this study as background data. We also attended workshops and conferences in Norway initiated by local nongovernmental organizations campaigning against FGC.

\section{Procedure}

Several preliminary meetings with Somali and Gambian women were arranged to translate and clarify common words used to describe the procedure and ritual of FGC. Interviews were mostly conducted in either English or Norwegian; four used their first language and translators had to be used. The authors performed the interviews either individually or together. All interviews involved semistructured and openended questions. To capture specific childhood experiences, respondents were asked for their own narrative about the ritual and the cutting. We stressed that they should talk about their experiences as freely as possible. In additional, various prompts were provided to help them elaborate on their experiences.

After the narratives had been told, the focus shifted to elaboration of aspects of the meaning-making process. The participants were interviewed twice. In total, we used three different translators who also served as cultural advisors during discussions throughout the research process. One of the cultural advisors was also present during background interviews with 15 circumcisers in the Gambia. The researchers and the cultural advisors attended several group discussions on the content of the interviews. Most interviews were audiotaped and transcribed verbatim.
The analysis was inspired by grounded theory. In each case, the data were clustered according to the following categories: use of metaphors, construction of narratives, and the process of instruction, education, and supervision. Core concepts were created by being grouped across the individual cases. The theoretical framework was based on educational psychology and cognitive and narrative psychology, using metaphors and narratives as instruments in meaning-making.

\section{Results}

The following two strategies for preparing a girl for the upcoming circumcision are presented as prototypes, representative of the type and structure of information given.

\section{Closed information strategy from the Gambia}

Nimba had recently celebrated her fourth birthday when she was told that something fantastic was about to happen to her. She saw that her grandmother and mother as well as her aunts were busy preparing for a ceremony. They told her that it would be a big celebration with lots of people coming, but where it would happen was a secret. "I was told I was going to a ceremony. I asked more about it but they said it was a secret. I only knew everybody would be there wearing their best clothes and there would be lots of presents. I was so excited." The evening before the ceremony, Nimba's hair was carefully plaited, she got to see her new clothes, and was given her favorite food. The next day she was woken up early, washed and dressed, and ate a little breakfast. She was then blindfolded and led away by her mother and aunt.

\footnotetext{
"When the blindfold was removed, I was puzzled to see that I was in our neighbor's house. I was sitting on a mat, there were five of us. I only remember one of the girls that I already knew. Then they took the first girl, blindfolded her again and took her into another room. As I was waiting I heard the screams and I became very skeptical. I finally understood that this was not as rosy as they said it would be. I thought, 'This isn't right'. Then I was led into the bathroom. I can remember the cement floor. It all went so fast, and I couldn't fight it because they held my arms and legs. Then I felt the pain ... I screamed ... they had to carry me out."
}

When Nimba was cut, none of her family was present. She remembers seeing her mother and grandmother afterwards when she was lying in another room with the four other girls. The girls lay to heal in this room for two weeks. For the first few days, they could not walk and had to be helped to the toilet. During those two weeks, they received many visitors. 
Nimba remembers everyone telling her how important this was for her and how brave she had been. Nimba clearly remembers the initial excitement, but she also remembers a trace of uncertainty because they had never talked about what was going to happen. The cutting came as a total shock to her, and for the next few weeks she continued to have the feeling that it was not right. Gradually, however, she became a proud girl. She developed a sense of pride in having been through the ritual and of what she had become: a clean girl.

Circumcisers in the Gambia often use drums and loud singing to suppress the screams, as well as blindfolds to shield the girls from seeing the cutter. They explain that the girls should never know who cut them, so subsequently they cannot point out the cutter and frighten uncut girls. It is also stressed that uncut girls should know as little as possible about the circumcision. Such knowledge would only upset the child and make her run away. "They are protected", explained one circumciser, "because they have no idea of what's going to happen".

\section{Partly open information strategy from Somalia}

Yasmin was six years old when she was cut. She lived in a large town with her family, who were financially well off. Yasmin had known for a while that the big day was coming. When her mother told her that the circumciser would be coming next Friday, Yasmin was extremely happy and immediately ran to tell her friends that it was finally her time. She remembers the triumphant feeling: now she would be a better girl than they were, because they were not yet cut. Her mother braided her hair, trimmed her nails, gave her a new dress, and made her go to bed early. Over the previous months, Yasmin had talked to several older friends and they had told her about the procedure.

"Several of my older friends had gone through it and they were happy. They said it would hurt, but the pain would pass. But I definitely found out that they weren't right about the pain part. I got local anesthetic and never felt the pain when I was cut and sewn. I was afraid of the needle ... I screamed and cried ... they were holding me hard. My mother left the room, she couldn't take it. The pain came later."

The circumciser came from the local hospital. He was instructed in the process by Yasmin's aunt, who "was the expert on how women should look down there". After the effects of the local anesthetic had worn off, the pain hit Yasmin hard. She had problems urinating because of the severe pain. Her mother tried to comfort her and also explained that if she did not urinate her belly would explode and she would die. Yasmin was very scared, but gradually she got better and managed to urinate when she was carried to the toilet. For 14 days she had to lie still, and her mother comforted her. After 10 days her aunt came back to check on Yasmin's genitals. "I remember she was very happy and said it was perfect! It didn’t hurt much anymore and I was proud ... very proud. I was happy ... and I was normal." She had become "smooth"; her genitals had been modified and were now "clean, smooth and beautiful".

\section{Five phases of learning}

There are variations and differences in how our informants, subject to each of the two strategies, experienced the information and preparation they received prior to the circumcision. The description of the procedure itself also varied: from traumatic experiences to lesser degrees of traumatic stress and to a procedure that hurt at first but then became less painful. Seeking to explore the meaning-making process, we identified in the interview material five phases where the girl child is provided with information. The five phases are based on the two strategies; there is much in common after the circumcision has been performed, but significant differences in the two initial phases.

In the initial preparation phase, the Somali girl child is gradually presented, both directly and indirectly, with certain social rules: uncut girls are not clean and they will not be able to get married, be respected, or be included in local society. If an unclean girl slaughters a goat or a hen and prepares the food, the food will be tainted and will not be proper halal. Our Somali informants frequently mentioned that older cut girls may exclude uncut girls from play. When cut girls enter a room, the uncut girls are asked to leave. Adults also differentiate, allowing only cut girls to pour tea for the women. One informant describes her restlessness when she was six years old, and she was cut the following year:

"I was ready. I begged my mother to let me be circumcised soon. I was afraid of it, but I was more afraid of being bullied at school. I had seen 15 -year-old uncut girls being bullied. All the children were divided into two groups, the cut and the uncut. I wanted to belong to the group that had been circumcised."

The next learning phase is the preparation phase. For the Somali girls, this starts about one year prior to the procedure, when the girl is told that within a year she will be ready for circumcision. The further information she receives is a mixture of direct information from adults and communication with older cut girls, which is encouraged. 
It is the mother's responsibility to monitor what sort of information her daughter receives. She does this by paying close attention to whom her daughter talks, and then checks with their mothers what sort of experiences their daughters had and what sort of stories they are likely to pass on. If her daughter receives scary stories focused on pain, it is up to the mother to "correct" and supplement them. When a girl is informed that she is ready for circumcision she will say this at school and tell her friends. Older girls might then come to the family's home and ask the mother to confirm that the daughter is about to be cut. The mothers reported that the uncut girls are very active in this process: "They find it very exciting to explore who has done it and they engage actively in exploring what the older girls went through." It is the grandmother who is responsible for making sure the ritual takes place, and the mother has a vital supportive role. They must select a circumciser, arrange for a proper circumcision, and monitor the process carefully.

The first two phases described here are more explicit for the Somali girls, who are exposed to the partly open information strategy. The Somali girls are primed and motivated actively to gather knowledge about the forthcoming ritual. This is not the case for the Gambian girls, who are exposed to the closed information strategy and who mostly gain their knowledge directly from the ritual itself and from the later learning phases.

The ritual and explanation phase is rich in information, which, depending on the girl's age, may also include formal instruction. It is vital to the honor of the girl and of her family that she does not scream during the cutting. She must endure her pain "like the grown-up woman" she is about to become. After the circumcision, the mother and grandmother follow up the healing process, help the girl to urinate regularly, and make sure she does not walk for two weeks in order for the wound to heal. They must then ensure that she is properly inspected to check that the circumcision has been satisfactorily performed, after which they make the result public. The ensuing party is a celebration of the girl's successful circumcision, and also a celebration for the grandmother and mother who have performed their duties properly. The extent of further formal instruction on the topic depends on the girl's age. As a minimum, this education is as one mother describes it:

"You have to make her understand the importance of taking care of her vagina and make sure she understands the severity and gravity of it; if she isn't careful she will never get married, she will be excluded from social life and she will be a disgrace to her family and to herself."
The reports of the participants reveal variations in the content and the degree of formal instruction in the ritual and explanation phase. These variations are connected with the age of the girls and whether the ritual was performed individually or in a larger group. The rituals performed in groups tend to carry more ritual fanfare and more formal instruction. Several of the older Gambian women who were cut at the age of 11-12 years reported that formalized instruction with, designated teachers went on for weeks and sometimes months. They learned traditional knowledge such as that contained in songs, dances, religion, and cultural norms, how to behave as a woman, and about menstruation, pregnancy, respect for elders, and food taboos. The formal instruction was given by a designated teacher known as a "Kantallalo" and in the form of songs, dances, recitation, repetitions, and questions and answers. It was not uncommon for the girls to establish a relationship with their Kantallalo in such a way that they could also ask her questions after the formal instruction ended. The participants reported that several of the educational topics that were previously taught by the Kantallalo are now taught in school.

If the girl is considered to be too young to profit from formal education in this phase, the formal education comes in a later learning phase that can be characterized as the education and conversation phase. This phase starts when the girl reaches puberty, at around 12 years of age. The previous role and responsibility of the Kantallalo is divided between the school, the mother, and other female family members. It is the mother's responsibility to emphasize to her daughter the importance of being an honorable woman in order to be married and what this means when it comes to sexuality.

The confirmation phase can be defined as a continuous process of confirming and reassuring the importance of the cutting after it is performed. Once the pain has subsided and the festivities are over, newly cut girls enter a new role, in that they are now one step closer to being honorable young women ready for marriage. They are admired by those who have not yet been cut, and are acknowledged by those who have already been through the ritual. They have become part of a broader fellowship. For girls aged around 6-7 years, circumcision represents an important rite of passage. They are questioned by uncut girls, serving as witnesses and deliverers of promises in the dissemination of information to the uncut girls. In this phase, the girls are instructed about why it is important to perform circumcision. The girls are told that if they were not cut they would exhibit abnormal social conduct through their sexual activity. They would be tormented by strong sexual desire and the clitoris would grow to the size 
of a male penis. These and similar explanations are repeated and can be described as confirmative talk.

In this study, the Somalian girls were cut at the age of 6-8 years and the Gambian girls at around four years of age. In the Somalian approach, there is more interaction between mother and child before the procedure. The Gambian girls have little preparation and report being psychologically unprepared to a greater extent and also a feeling of being deceived.

When a girl has received and internalized the defined information, she has attained the educational goal of knowing how to behave honorably. As soon as she reaches the right age, she is ready to be married, and a suitable husband is selected, and then the mother becomes a grandmother and has the responsibility for making sure her grandchildren are properly circumcised.

\section{Understanding from a child's perspective}

During the partly open process in Somalia, there is limited talk between women and girls about the upcoming cutting. A Somali girl who was infibulated at the age of seven years had been told by her grandmother that the ritual would "make the girl like her mother and grandmother". When she later asked her mother if the ritual was the same as that her older brother had gone through, her mother confirmed that it was similar. As she approached the ritual, she knew at the age of seven years that it was important to change something in her vagina in order to become clean. She also knew that it would hurt, that everybody did it, that it would make her like her mother and grandmother, and that the procedure would be followed by a big celebration. During the recovery period, she was informed that she was now "closed" and that it was her responsibility to "keep it beautiful, clean, and closed" until marriage. Both the Somali and the Gambian informants recalled that there were no options for engaging in open exploratory talks about the circumcision after the ritual had been performed. As children and adolescents, they saw it as a partly taboo subject, and none of the informants recalled that they themselves had initiated a conversation about it with their mother or other grownups. As one girl explained, "I remember as a teenager I was afraid to ask my questions because she could interpret it to mean that I was interested in having sex. We couldn't talk about it at all."

At the age of 12 years, one informant and her friend were playing; they were climbing high in a tree. She fell down and hurt her shoulder. She cried, and both of them became scared and ran home. They were met by an aunt who rushed towards them, stopped, and immediately started inspecting her niece's vagina to see if the infibulation was still intact. "And then she said I was all right. I was puzzled by this ... because I didn't know it was that important." The girls were then told to be more careful, and nothing more was said by the aunt. The two girls concluded that they would have to be more careful with "that place down there".

When our informants recalled their childhood experiences, the most common way of explaining why their mothers and grandmothers performed the ritual was that it was done "out of love". It was a tradition that was never questioned, and scarcely ever explained or talked about in an educational manner. Although the adults offered limited verbal information about the ritual, the girls themselves would talk about the topic with their peers. A few of the informants said that they had the feeling it was all wrong, and they channeled their anger towards their mothers and grandmothers. After they had left their home country and settled abroad, their reflections on the practice and the formulation of unanswered questions gained momentum. However, before they became aware that not all girls were cut, most of the respondents reported that they had very few critical reflections on and questions about the practice.

\section{Discussion}

The meaning-making process of the girls in connection with FGC was carefully monitored and supervised by their mothers, older sisters, grandmothers, and other women. The educational goal was that the girl should become a clean and honorable woman. This is achieved when the girl has performed the ritual, has understood and accepted its importance, and finally passes it on to the next generation. In order to reach this educational goal, girls are provided with formal and informal instruction structured in what we have identified as five phases of learning. The girls' meaning-making process is stimulated by their introduction to a set of metaphors for constructing their first meaningful narratives.

When our informants spoke of the ritual and the meaning behind it, their descriptions were rich in metaphors. Lakoff and Johnson ${ }^{17}$ argue that metaphor is a natural phenomenon, and a natural part of our thought and language. Metaphors are not only about words and how we talk; they are also about conceptualization and reasoning. Which metaphors we choose and what they mean will depend on the nature of our bodies, our interactions with the physical environment, and our social and cultural practices. ${ }^{17}$ Theories and research behind metaphors explore how, often unconsciously, they become building blocks in the understanding of aspects and dimensions of our experience. This is typically the case with human emotions, abstract 
concepts, mental activity, social practices, and so on. Even though most of these can be experienced directly, none of them can be fully comprehended on their own terms. Instead, we must understand them in terms of other kinds of entities and experiences, ie, understanding via metaphor. ${ }^{17}$ The cognitive importance of metaphor in instructional settings is acknowledged; it is argued that metaphor can play a central role in the pedagogical process of making what is learned more explicit. ${ }^{18}$ Good metaphors suggest new connections by picking out an illustrative and familiar example from a certain category. If this is grouped with another example from another category not related to the metaphor category, a relevant similarity is created.

"Being like your mother" is a prototypical example of the new class of category that is linked with the unfamiliar category of FGC. The girl's cognitive structures or schemas are expanded, whereby links are made between the new concept and previous experiences are grouped into familiar categories. Being like your mother and grandmother is desirable, it is a part of growing up, and for a little girl both her mother and grandmother are familiar, clearly defined concepts. The child also finds the same clarity in the concept of being "clean" versus being "unclean". The key to understanding the meaning of the new category of FGC and the comprehending metaphors is that both processes are bound up with activities. It is not simply a matter of hearing and understanding words, it is about acting in one's surroundings. The learner classifies and is corrected; she sorts, perceives similarities and differences, and reclassifies. The same activities are done with the metaphors, ie, classifying, building new links, and testing hypotheses suggested by the new class-inclusion relationship. ${ }^{18}$ Because they are not allowed to handle food in the kitchen or serve tea, the Somali girls are told and shown that they are not "clean" and that they are not living up to the two metaphors of "being like your mother" and "being clean".

Several of the infibulated Somali informants referred to the outcome of their circumcision as "being smooth". In their childhood, they had become familiar with the concept of "being smooth" and linked this to esthetics. Explanations of the smooth esthetic were often followed with a quick hand gesture indicating that you could stroke a closed and smooth genitalia that was free from any external visible parts. Somali women often consider the infibulated genitalia as beautiful and sexy. ${ }^{19,20}$ Shweder ${ }^{21}$ has pointed out that being smooth is not only popular but fashionable, and that unmodified genitals are seen as ugly, unrefined, uncivilized, and even not fully human.
Bruner argues for the narrative as an instrument for meaning-making because, in understanding cultural phenomena, people do not deal with the world event by event but rather frame events in larger structures. ${ }^{22}$ Creating narratives is a cognitive process that serves understanding by organizing events and happenings into frames of meaning. ${ }^{23}$ Within narrative psychology, narrative structuring and plots are essential to the meaning-making process. "Narrative structuring operates by configuring actions and events into a temporal whole. As concepts serve to give meaning to particular objects and actions by giving them a categorical identity, plots serve to give meaning to particular happenings and actions by identifying them as contributors to the outcome of an episode." 23

Many of the daily life experiences of a child occur within an accustomed setting with familiar people, and do not entail the need for extended meaning-making. Through participation in daily activities, the child develops cognitive schemas or scripts that act as a framework for sequences of familiar situations. ${ }^{24}$ The script serves as an adequate means for understanding events that conform to the expected, but when the unexpected occurs, the meaning becomes unclear. One of the chief functions of a narrative is to help the child deal with situations and experiences that are contrary to the expected. The narrative process is triggered by the unexpected; it reviews the unusual event in order to make sense of it. ${ }^{23,25}$

The two newly circumcised girls who climbed a tree reached a turning point in their understanding, which contributed a new understanding and meaning to the larger narrative about FGC. After falling from the tree, the girl was puzzled when her stitches were inspected by her aunt: "I didn't know it was that important." The plot in this episode constitutes a turning point in her understanding of the importance of FGC, clarifying the importance of and defining a conclusion on the need to be careful. In this and in similar reported episodes, the plots are about obscurity and not understanding. This is what structures the narrative. Lack of knowledge is the motive for constructing the narratives from all the episodes that are defined by the plot as having something to do with the child's puzzlement and attempts to understand FGC. Our informants mentioned a range of similar episodes, ie, not being allowed to participate in food preparation or serving tea, being teased about being uncut, the positive and overwhelming ceremonies after the ritual, and praise for having been "such a strong girl" during the cutting. The plots in such episodes define new meaningful components that bring clarity to the girls' ongoing composition of their FGC narrative. Commonly mentioned 
metaphors are open-closed, clean-unclean, child-grownup, esthetic-ugly, and included-excluded.

If a metaphor continues to make sense after being tested both in real life and cognitively by creation of a relevant similarity between two categories, then it passes into literal truth, whereas the metaphor itself becomes "dead". ${ }^{18}$ For our informants, the metaphors gradually made sense and became literal truth, and then ceased to exist as metaphors. Having served their purpose, they became "dead metaphors" and turned into explanations in themselves. In this context, we may note how the metaphors highlight the cultural ideas of being clean and honorable, while hiding matters such as medical issues and other possible rationales behind the ritual.

As argued above, the plots and specific meanings from different episodes are created in context, in play, and in social conduct. The FGC narrative is constantly readjusted and shaped. Through this process of narrative structuring, the girls achieve "an interpretation of life in which past events and happenings are understood as meaningful from a current perspective of their emplotted contribution to an outcome". ${ }^{23}$

However, the girls' learning process was actively stopped, in part as a result of the strong cultural regulation of communication about FGC. The strict limitations on how one can talk about FGC act to restrict the natural exploration and critical discussion that could have developed further and shaped the FGC narrative. Our informants' childhood and adolescent explanations and understanding of FGC must be characterized as limited, based on their use of metaphors and circular and tautological explanations like "that's the way it is", "it is necessary", "that's how we do it", and "we have always done it". The mothers" and grandmothers' explanation that "we do it out of love" indicates that they love the girls, and if the girls oppose the ritual, they are automatically rejecting their love. This is also another example linking honor and morality to the concept of cutting, which characterize the knowledge as morally embraced.

Green $^{26}$ argues that it is difficult to provide religious instruction without the use of metaphors because of lack of empirical data. We could argue that there are similarities between a child's first religious instruction and teaching about FGC. The abstract subjects of God and death and about FGC are made understandable through metaphors which both highlight and conceal certain aspects of the phenomena explained.
With FGC, the learning process is deemed a success when the educational goal has been achieved, ie, the circumcision ritual is accepted as a necessity, the girl is proud of it, and later on it is passed on to her own daughters. The educational goal has become established in thought, in language, and in conduct, and yet this learning process has been halted at the level of tautological explanations, not least because of the strict communication rules that effectively regulate open discussion. The communication convention defines the rules for talking about FGC, ie, what can be said, in what ways, at what time, and by whom. The tautological explanations based on half-understood ideas convey just enough knowledge for girls to be able to accept the ritual and carry on the tradition without questioning it, at least not openly.

In contrast, if there were a deliberate educational goal that involved the learners engaging in explorative discussions and internalizing knowledge into a reflexive mode of thinking, the educational process would have to be brought to the next level of learning. That would require introducing a metalanguage of FGC for formulating words and characteristics beyond the realm of the limiting metaphors. It is this level of education that needs to be fostered in settings where open and explorative discussion can be encouraged, and where the child or adolescent is motivated to ask questions and participate actively. The lack of these characteristics makes the knowledge embodied, and it is not being abstracted and cognitive accessible in a critical reflexive mode of thinking.

Tostan's community-based educational program provides a good example of the educational components of promising programs and approaches in terms of ending FGC. This program aims to empower women through a broad range of educational and health-promoting activities to define and pursue their own goals better. One of the key components is the creation of a forum in which women can safely engage in free and equal discussion about their challenges and problems, and in which the subject of FGC is freely debated and a trustworthy alternative to FGC is introduced. The strategy is to launch a process of basic education and discussion that spreads to public discussion and public declaration against the practice in order to achieve a collective shift in convention. ${ }^{13,27}$

\section{Conclusion}

This study has expanded the research on individual meaningmaking of FGC among children and adolescents by identifying and describing the informants' learning process. We have shown how metaphors serve as building blocks in the 
construction of narratives, and how the narratives structure the human experience, in this case integrating meaningful knowledge of FGC in a way which is only minimally accompanied by formal instruction.

The learning process is carefully monitored and regulated, and can be structured or divided into five phases of learning. The educational goal is clearly defined, although the learning process is highly informal. There is little formal instruction; it is a matter of learning by doing, and girls get feedback by corrections and praise for their conduct. The lack of directness in the educational process is compensated by the use of metaphors, which in themselves are unclear. This lack of clarity activates narrative processing and finding clarity is the motivation for such processing. In their daily lives, the girls are offered a rich set of metaphors that can help them to construct their FGC narrative. We have seen how the girls experience a range of episodes that are FGC-related in an indirect and subtle way. These episodes provide constant opportunities for working with their metaphors and further developing their own narratives. The shaping of the child's understanding is carefully monitored by the mother, but it is left largely to the girl herself and her peers to complete the process of making meaning from FGC. However, the educational process is then brought to a halt, stopping short of explorative and critical reflexive thinking, again in line with the cultural educational goal.

The "partly open information strategy" and the "closed information strategy" described here differ in their approaches, which in turn create different pathways for gathering of knowledge, but the outcome of the education process still seems to be similar. The informants seem to end up with a relatively similar knowledge and understanding. In both approaches, the limited instruction and explanations are primarily based on tautological explanations, a closed system of knowledge taken for granted that never becomes explorative. The knowledge tends to be deeply internalized, embodied, and morally embraced. In the interviews, our informants consistently presented a limited cognitive frame of understanding that lasted until they left their home country and went abroad. Only a few informants reported that as children they had felt "it was all wrong" and directed their anger towards their mothers and grandmothers. This might indicate that the level of meaning-making is sufficient within the cultural context, and is maintained through strict conventions. It could also mean that the internalized knowledge and the FGC identity remain protected within the cultural context, but become vulnerable when challenged from outside. If the learning process stops at the level of learning metaphors, this may confuse and give unclear knowledge, rather than stimulate the development of critical reflexive thinking. ${ }^{18,26,28,29}$

\section{Implications}

The findings of our study are relevant to programs that target change through education with the intention of reaching a level of critical reflexive thinking. There are various types of interventions that aim at ending the practice of FGC, and the educational component is a significant element of these both in countries performing the ritual and abroad. When refugees and migrants from areas where FGC is practiced come to countries where the practice is forbidden by law, they are often met with a range of actions and programs that are intended to alter any positive views they might have had about the practice. Our study may help to provide a better foundation for understanding these immigrants' previous learning process and the characteristics of the knowledge they may have internalized. This could in turn assist in the further development of educational programs and help facilitate and differentiate the learning process by identifying and implementing educational stimuli that can promote critical reflexive thinking.

\section{Limitations}

The purposive sampling in Norway gave us participants who had been exposed to two different strategies of preparing for the ritual, and who had a variety of FGC experiences. This provided us with rich empirical data to explore the participants' meaning-making on the basis of the instruction, education, and information given to them. The quality of the reported narratives is challenged by the retrospective approach taken for this study. Interviews of children and adolescents could shed more light on how children make meaning of FGC. The meaningmaking is applicable to the cultures studied, but could be more or less different in other ethnic groups. The fact that one of the interviewers was male did not appear to limit the exploration of sensitive issues in the interviews. On the contrary, several participants reported that it was a relief to talk to a complete outsider who was not a Muslim, and not even a woman.

\section{Further research}

The effect of educational programs leading to a collective convention shift is explained by convention theory. ${ }^{7,8}$ It is our understanding that further exploration of the educational and psychological factors leading up to the shift would give additional knowledge and provide further insight for 
program design. Further investigation is needed to identify what sort of educational stimuli are most effective on an individual basis in terms of enabling critical reflexive thinking on the tradition of FGC, as well as on other potentially harmful traditions. When behavior-change communication programs in a foreign setting are designed, it would be helpful to have specific research on the extent to which the individual woman can acquire new and contradicting information about FGC. Will she be able to internalize the new information as an addition to her existing cognitive structure or schemas? Or is it necessary to discard totally the old embodied and morally embraced knowledge and, if so, what would the educational process look like? And what could be the psychological and emotional cost of such a process?

\section{Acknowledgments}

This study was funded by the Norwegian Ministry of Children, Equality, and Social Inclusion. We gratefully acknowledge the support of Dag Skarstein, Mona Iren Hauge, Geir Borgen, and Neneh Bojang, and their participation in discussions.

\section{Disclosure}

The authors declare that they have no competing interests in this work.

\section{References}

1. World Health Organization. Female genital mutilation, Fact sheet 241. Geneva, Switzerland: World Health Organization; 2012. Available from: http://www.who.int/mediacentre/factsheets/fs241/en/. Accessed August 23, 2012.

2. Johnsdotter S. Created by God: How Somalis in Swedish exile reassess the practice of female circumcision. PhD dissertation. Lund, Sweden: Department of Social Anthropology, Lund University; 2002.

3. Johnson MC. Making Madinga or making Muslims? Debating female circumcision, ethnicity and Islam in Guinea-Bissau and Portugal. In: Hernlund Y, Shell-Duncan B, editors. Transcultural Bodies. Female Genital Cutting on Global Context. New Brunswick, NJ: Rutgers University Press; 2007.

4. Boddy J. Gender crusades: the female circumcision controversy in cultural perspective. In: Hernlund Y, Shell-Duncan B, editors. Transcultural Bodies. Female Genital Cutting in Global Context. New Brunswick, NJ: Rutgers University Press; 2007.

5. Boddy J. Wombs and Alien Spirits: Women and Men in the Zar Cult in Northern Sudan. Madison, WI: University of Wisconsin Press; 1989.

6. Talle A. Female circumcision in Africa and beyond: the anthropology of a difficult issue. In: Hernlund Y, Shell-Duncan B, editors. Transcultural Bodies. Female Genital Cutting in Global Context. New Brunswick, NJ: Rutgers University Press; 2007.

7. Mackie G. Ending footbinding and infibulation: a convention account. Am Sociol Rev. 1996;61:999-1017.

8. Mackie G, LeJeune J. Social dynamics of abandonment of harmful practices: a new look at the theory. Innocenti Working Paper. Special Series on Social Norms and Harmful Practices. Florence, Italy: United Nations Children's Fund; 2009.

9. Schelling TC. The Strategy of Conflict. Cambridge, MA: Harvard University; 1960.
10. Johnson MC. Becoming a Muslim, becoming a person: female 'circumcision', religious identity and personhood in Guinea Bissau. In: Shell-Duncan B, Hernlund Y, editors. Female 'Circumcision' in Africa. Culture, Controversy and Change. Boulder, CO: Lynne Rienner; 2000.

11. Shell-Duncan B, Hernlund Y, Wander K, Moreau A. Contingency and change in practice of female genital cutting: dynamics of decision making in Senegambia. Summary report. Washington, DC: Department of Anthropology, University of Washington; 2010. Available from: http://csde.washington.edu/ bsd/FGC/Contingency $\% 20$ and $\% 20$ Change $\% 20$ in $\% 20$ the $\% 20$ Practice $\% 20$ of $\% 20$ Female $\% 20$ Genital $\% 20$ Cutting.pdf. Accessed February 10, 2013.

12. United Nations Children's Fund Innocenti Research Centre. The Dynamics of Social Change: Towards the Abandonment of FGM/C in Five African Countries. Florence, Italy: United Nations Children's Fund Innocenti Research Centre; 2010.

13. Diop NJ, Askew I. The effectiveness of a community-based education program on abandoning female genital mutilation/cutting in Senegal. Stud Fam Plan. 2009;40:307-318.

14. United Nations Children's Fund Innocenti Research Centre. Changing a Harmful Social Convention: Female Genital Mutilation/Cutting. Florence, Italy: United Nations Children's Fund Innocenti Research Centre; 2005.

15. World Health Organization. Female Genital Mutilation. Programs to Date: What Works and What Doesn't. Geneva, Switzerland: Department of Women's Health, World Health Organization; 1999.

16. Askew I. Methodological issues in measuring the impact of interventions against female genital cutting. Cult Health Sex. 2005;7: 463-477.

17. Lakoff G, Johnson M. Metaphors We Live By. Chicago, IL: University of Chicago Press; 2003.

18. Petrie HG, Oshlag RS. Metaphor and learning. In: Ortony A, editor. Metaphor and Thought, 2nd ed. Cambridge, UK: Cambridge University Press; 1993.

19. Catania L, Abdulcadir O, Puppo V, Verde JB, Abdulcadir J, Abdulcadir D. Pleasure and orgasm in women with female genital mutilation/cutting. J Sex Med. 2007;4:1666-1678.

20. The Public Policy Advisory Network on Female Genital Surgeries in Africa. Seven things to know about female genital surgeries in Africa. Hastings Cent Rep. 2012;42:19-27.

21. Shweder RA. What about female genital mutilation? And why understanding culture matters in the first place. In: Shweder RA, Minow M, Markus HR, editors. Engaging Cultural Differences: The Multicultural Challenge in Liberal Democracies. New York, NY: Russell Sage Foundation; 2002.

22. Bruner J. Acts of Meaning. Cambridge, MA: Harvard University Press; 1990.

23. Polkinghorne DE. Narrative psychology and historical consciousness, relationships and perspectives. In: Straub J, editor. Narration, Identity and Historical Consciousness. New York, NY: Berghahn Books; 2005.

24. Hudson JA, Shapiro LR. From knowing to telling: the development of children's scripts. Stories and personal narratives. In: McCabe A, Peterson C, editors. Developing Narrative Structure. Hillsdale, NJ: Lawrence Erlbaum Associates; 1991.

25. Polkinghorne DE. Narrative configuration in qualitative analysis. Int $J$ Qual Stud Educ. 1995;8:8-25.

26. Green TF. Learning without metaphor. In: Ortony A, editor. Metaphor and Thought, 2nd ed. Cambridge, UK: Cambridge University Press; 1993.

27. Mackie G. Female genital cutting: the beginning of the end. In: Shell-Duncan B, Hernlund Y, editors. Female Circumcision in Africa. Culture, Controversy and Change. Boulder, CO: Lynne Rienner; 2000.

28. Lakoff G, Johnson M. Philosophy in the Flesh. New York, NY: Basic Books; 1999.

29. Ortony A. Metaphor, language and thought. In: Ortony A, editor. Metaphor and Thought, 2nd ed. Cambridge, UK: Cambridge University Press; 1993. 
International Journal of Women's Health

Dovepress

\section{Publish your work in this journal}

The International Journal of Women's Health is an international, peerreviewed open-access journal publishing original research, reports, editorials, reviews and commentaries on all aspects of women's healthcare including gynecology, obstetrics, and breast cancer. The manuscript management system is completely online and includes Visit http://www.dovepress.com/testimonials.php to read real quotes from published authors.

Submit your manuscript here: http://www.dovepress.com/international-journal-of-womens-health-journal 